\title{
Burning Mouth Syndrome: An Enigmatic Disorder
}

\author{
Javali MA
}

Department of PDS

Division of periodontics

King Khalid University

College of Dentistry

Abha.KSA

\section{Corresponding Author}

Javali Mukhatar Ahmed

Department of PDS

Division of periodontics

King Khalid University

College of Dentistry

Abha.KSA

E-mail: majavali@yahoo.com

\section{Citation}

Javali MA. Burning Mouth Syndrome: An Enigmatic Disorder. Kathmandu Univ Med J 2013;42(2):175-178.

\begin{abstract}
Burning mouth syndrome (BMS) is a chronic oral pain or burning sensation affecting the oral mucosa, often unaccompanied by mucosal lesions or other evident clinical signs. It is observed principally in middle-aged patients and postmenopausal women and may be accompanied by xerostomia and altered taste. Burning mouth syndrome is characterized by an intense burning or stinging sensation, preferably on the tongue or in other areas of mouth. This disorder is one of the most common, encountered in the clinical practice. This condition is probably of multifactorial origin; however the exact underlying etiology remains uncertain. This article discusses several aspects of BMS, updates current knowledge about the etiopathogenesis and describes the clinical features as well as the diagnosis and management of BMS patients.
\end{abstract}

\section{KEYWORDS}

Burning mouth syndrome, idiopathic, stomatodynia, xerostomia

\section{INTRODUCTION}

Burning mouth syndrome (BMS) is a painful and often frustrating condition. Some patients compare it to having burned their mouth with hot coffee. Although not a terribly common clinical complaint, it is in fact frequently encountered in a routine practice. The burning sensation may affect the tongue, the roof of the mouth, the gums, the inside of the cheeks and the back of the mouth or throat. From a clinicopathologic stand-point two forms of BMS is discussed: primary BMS, the idiopathic form of the disorder, and secondary BMS, which results from local or systemic disorders that may respond to appropriately directed therapy. ${ }^{1}$

Idiopathic form of BMS is discomfort or pain affecting people with clinically normal oral mucosa, in whom a medical or dental cause has been excluded. ${ }^{2}$ BMS is usually described as a burning quality, which may vary in severity from aggravating or an־noying to agonizing as if the affected area had been scalded or had touched a hot griddle. Tingling and numbness are other features that may be experienced.

\section{Definition and Terminology}

BMS is synonymous with stomatodynia, oral dysaesthesia, glossodynia, glossopyrosis, scalded mouth syndrome,sore tongue and stomatopyrosis. ${ }^{3}$ The International Association for the Study of Pain and International Headache Society defines it as a 'distinctive nosological entity', including 'all forms of burning sensation in the mouth, including complaints described as stinging sensation or pain, in association with an oral mucosa that appears clinically normal in the absence of local or systemic diseases or alterations. True idiopathic BMS is defined as a burning pain in the tongue or other oral mucosal membrane in absence of clinical and laboratory abnormalities. ${ }^{3}$ In brief, the term is applied to those patients with chronic oral pain 
or burning sensation of the mouth which appears to be medically unexplainable, due to the absence of obvious visible lesions or relevant systemic disorders. ${ }^{2}$

\section{Epidemiology}

This disease has a prevalence that varies from 0.7 to $15 \%$ in the general population and has an average duration of two to three years. ${ }^{4}$ It predominantly affects middle-aged women in the postmenopausal phase and in a ratio of 7:1 when compared to men. ${ }^{5}$ Few studies have mentioned the presence of BMS in earlier ages which indicates that its prevalence increases with age. ${ }^{4}$

\section{classification}

Burning in the mouth can take on two different forms: a primary or idiopathic form of the disease for which there is no evident clinical explanation, and a secondary form derived from the presence of local or systemic factors.

According to Lamey and Lamb, the symptomatology associated with BMS may be classified in three types, as shown in Table $1 .^{6}$

\section{Table 1. Classification of BMS according to symptomatology.}

\begin{tabular}{|c|c|c|}
\hline Types & BMS symptomology ${ }^{6}$ & $\begin{array}{l}\text { Factors associated with BMS } \\
\text { in each type }{ }^{7}\end{array}$ \\
\hline 1 & $\begin{array}{l}\text { Symptoms are not present } \\
\text { when the patient wakes up, } \\
\text { but they will appear and } \\
\text { increase during the day }\end{array}$ & Moderate anxiety disorders \\
\hline 2 & $\begin{array}{l}\text { Symptoms are present all } \\
\text { day and night and strongly } \\
\text { associated with anxiety. }\end{array}$ & Severe psychiatric disorders. \\
\hline 3 & $\begin{array}{l}\text { Symptoms are not present } \\
\text { during some days and are } \\
\text { associated with emotional } \\
\text { instability or a } \\
\text { Hypersensitivity reaction to } \\
\text { some foods. }\end{array}$ & $\begin{array}{l}\text { Emotional instability or al- } \\
\text { lergic reactions. }\end{array}$ \\
\hline
\end{tabular}

\section{Clinical Presentation}

BMS may occur in any tissue inside the oral cavity, although most often it is found on the two thirds of the anterior and on the tip of the tongue. ${ }^{8}$ These symptoms, which may occur individually or in combination, are usually bilateral but may be unilateral. Occasionally, the patient will complain the entire mouth burns. ${ }^{9}$ The complaint of burning and numbness may be noted concurrently. The pain of BMS is usually moderate to intense. BMS affects women much more commonly than men, primarily periand postmenopausal females. Once BMS begins, it may persist for many years. Patients who have it may awaken with no pain only to find that the burning sensation grows progressively worse during the day. They may have difficulty falling asleep. The discomfort and restlessness may cause mood changes, irritability, anxiety and depression.

\section{Etiopathogenesis}

The cause is unknown, and we found no good etiological studies. Local and systemic factors (such as infections, allergies, ill-fitting dentures, hypersensitivity reactions, and hormone and vitamin deficiencies may cause the symptom of burning mouth(Table 2,3)..$^{10-14}$ Other possible causal factors include hormonal disturbances associated with the menopause psychogenic factors (including anxiety, depression, stress, life events, personality disorders, and phobia of cancer and neuropathy in so-called supertasters. ${ }^{10,15-17}$ Support for a neuropathic cause comes from studies that have shown altered sensory and pain thresholds in people with BMS. ${ }^{18}$

\section{Table 2. Local Factors That May Results In BMS Like Symptoms.}

\begin{tabular}{ll|}
\hline 1 & Tongue disorders \\
\hline 2 & Temporomandibular Disorders. \\
\hline 3 & Salivary gland dysfunction. \\
\hline 4 & $\begin{array}{l}\text { Trauma. (Physical, traumatic ulceration, denture irrita- } \\
\text { tion, chemical,Thermal(reverse smoking). }\end{array}$ \\
\hline 5 & Parafunctional habits. \\
\hline 7 & Foliate Papilitis \\
\hline 9 & Xerostomia. \\
\hline 10 & Oral premalignancy or malignancy. \\
\hline & Herpes simplex and Herpes zoster virus infection. \\
\hline
\end{tabular}

At present, most accept that the etiology is multi- factorial with mounting evidence for a physiological basis. Axonal degenerative changes have been demonstrated in glossal terminal nerve fibres and sensory changes have been shown to be present in burning mouth patients, particularly perception of heat, cold, taste and nocioceptive stimuli. ${ }^{19}$ Abnormalities in trigeminal somatosensory evoked potentials have been demonstrated as well. ${ }^{20}$ This, plus other data, strongly suggests that there is a dysfunction of the small diameter afferent sensory fibres in burning mouth syndrome. Imaging studies in patients have also suggested central nervous system changes. ${ }^{21}$

\section{Management and Prognosis}

The first step in treating a patient with BMS is an accurate diagnosis (Table 4). Successful management of BMS, demands co-operation among the dentists, the patients and the health professional. An effective approach for BMS patients should be based on a detailed clinical history and careful clinical examination (Fig 1, 2). The history should include a review of major illnesses, systemic diseases and medications usage as well as other conditions associated with BMS.

First, any oral conditions causing the burning sensations should be investigated. For dry mouth, advise to drink more fluids or saliva replacement products. An oral swab or biopsy may be used to check for thrush, which is a fungal infection; thrush can be treated with oral antifungal medications. Any irritations caused by sharp or broken teeth or by a removable partial or full denture should be eliminated. Eliminate mouthwash, chewing gum, tobacco 
Table 3. More Generalized Disorders That May Produce BMS Like Symptoms.

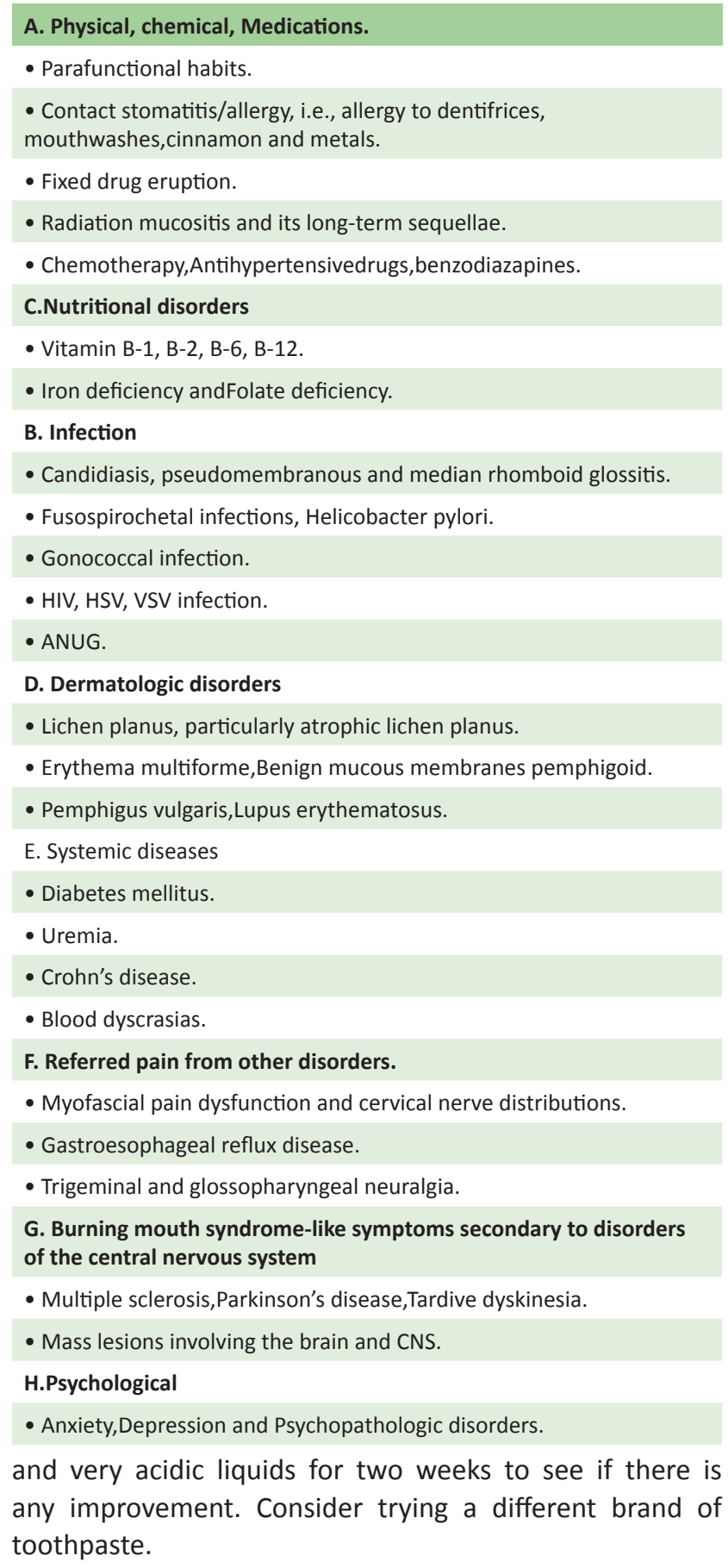

Look up the side effects of any medications you are taking (such as those used to treat high blood pressure). If any of your medications are reported to cause a burning sensation in the mouth, ask your physician to prescribing a substitute medication. Also, some medications can cause dry mouth, which might aggravate the condition.

If on evaluation, no oral conditions are causing the burning sensation and the steps listed above do not resolve the problem, disorders such as diabetes, abnormal thyroid conditions, Sjögren's syndrome, mineral deficiencies or food allergies should be investigated. This usually involves referral to physician and the use of blood tests.

\section{Table 4. Diagnostic Testing For BMS-Like Symptoms.}

\section{Salivary testing, including but not limited to}

- Objective testing of salivary flow rate (modified Schirmer test).

- Salivary $\mathrm{pH}$ testing.

2. Fungal and possibly bacterial or viral cultures.

3. Laboratory studies.

- Complete blood count.

- Vitamins.

- Blood sugar

4. Oral biopsy with immunofluoresence in case that one or more of themucocuteneous disorders is suspected.

5. Allergy testing.

6. Clinical assessment.

- Cranial nerve examination.

- Musculoskelleton examination.

- Gastroentology consult if GERD is suspected.

7.CT or MRI if necessary depending on the deferential diagnosis and clinical findings

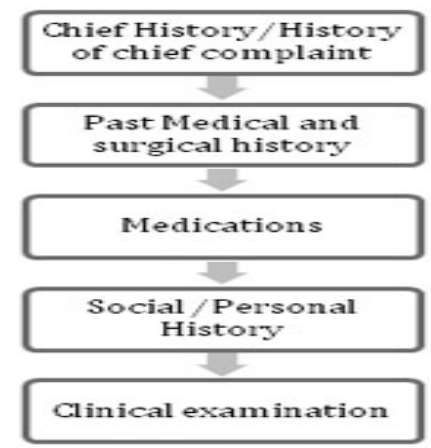

Figure 1. Evaluation of patient with BMS like Symptoms.

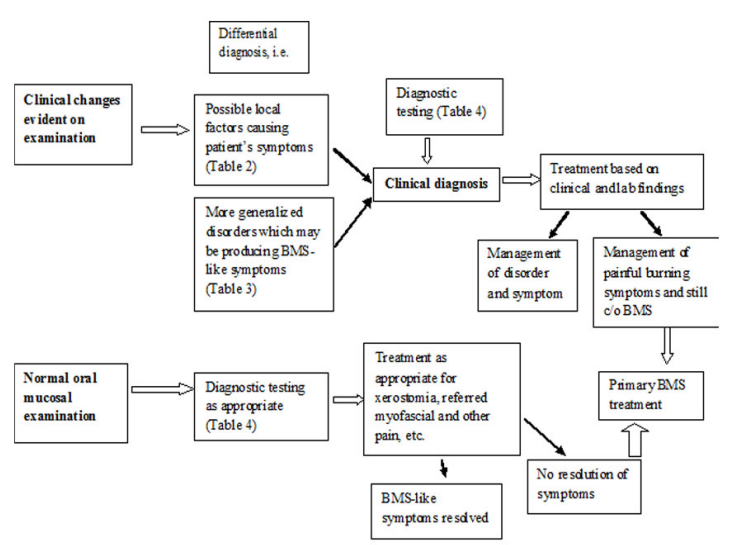

Figure 2. Clinical examination, diagnosis and management.

It is also appropriate to employ the concept of escalation of therapy, i.e., topical versus systemic therapy, using the alternative with the fewest side effects first. With a possible neuropathic etiol-ogy in mind, the use of topical capsaicin should be considered. It has been shown that topical application of capsaicin can partially or completely mollify the pain in primary BMS. ${ }^{22}$ A pilot study using systemic capsaicin has also been report-ed. ${ }^{23}$ It was shown to be therapeutically effective for short-term management of BMS, although major gastrointestinal side effects were 
noted. Topical or systemic uses of a variety of medications have been considered as treatment for primary BMS. Woda et al. studied the effect of local application of clonazepam for patients with BMS and showed significant result. ${ }^{24}$ Use of alpha lipoic acid showed improvements in patients with $73 \%$ after a period of 12 months. ${ }^{25}$ Finally, it has been pointed out that in cases of BMS resistant to other therapies, a psychologi-cal origin should be considered. Bergdahl et al. in their study reported good effect of cognitive therapy in patients with resistant BMS. ${ }^{26}$ Grushka et al. reported at least partial remission in nearly 50 percent of patients with BMS with seven years of onset of their symptoms.9 They also reported a change from constant to cyclic burn-ing during the same time period for some patients still experiencing some pain. More recently, Sardella et al. in a retrospective study looked into the spontaneous remission rate of patients with this disorder. ${ }^{27}$ Their data showed complete spontaneous remission in three percent of patients within five years after the onset of BMS.

\section{REFERENCES}

1. Scala A, Checchi L, Montevecchi M, Marini I, Giamberardino MA. Update on burning mouth syndrome: overview and patient management. Crit Rev Oral Biol Med 2003;14:275-91.

2. Zakrzewska JM. The burning mouth syndrome remains an enigma. Pain 1995;62:253-7.

3. Merksey H, Bogduk N, eds. Classification of chronic pain. 2nd ed. Seattle: International Association for the Study of Pain Press; 1994.

4. Bergdahl M, Bergdahl J. Burning Mouth Syndrome: prevalence and associated factors. J Oral Pathol Med 1999; 28:350-4.

5. Tourne LPM, Friction JR. Burning Mouth Syndrome. Critical review and proposed clinical management. Oral Surg Oral Med Oral Pathol 1992; 74:158-6.

6. Lamey PJ, Lamb AB. Lip component of BMS. Oral Surg Oral Med Oral Pathol 1994;78:590-3.

7. Paterson AJ, Lamb AB, Clifford TJ, Lamey PJ. Burning Mouth Syndrome: the relation between the HAD scale and parafunctional habits. $J$ Oral Pathol Med 1995; 24:289-92.

8. Evans RW, Drage LA. Burning Mouth Syndrome. Headache 2005; 45:1079-81.

9. Grushka $M$, Ching V, Epstein J. Burning mouth syndrome. Adv Otorhinolaryngol 63:278-87, 2006.

10. Grushka M, Sessle BJ. Burning mouth syndrome. Dent Clin North Am 1991; 35:171-184.

11. Bergdahl J, Anneroth G, Anneroth I. Clinical study of patients with burning mouth. Scand J Dent Res 1994;102:299-305.

12. Maragou P, Ivanyi L. Serum zinc levels in patients with burning mouth syndrome. Oral Surg Oral Med Oral Pathol Oral RadiolEndod 1991;71:447-450.

13. Lamey PJ, Allam BF. Vitamin status of patients with burning mouth syndrome and the response to replacement therapy. $\mathrm{Br}$ Dent $J$ 1986;168:81-4.

14. Hugoson A, Thorstensson B. Vitamin B status and response to replacement therapy in patients with burning mouth syndrome. Acta Odontol Scand 1991;49:367-375.

15. Basker RM, Sturdee DW, Davenport JC. Patients with burning mouths. A clinical investigation of causative factors, including the climacteric and diabetes. Br DentJ 1978;145:9-16.

\section{CONCLUSION}

BMS is a multifactorial disorder with a physiological basis. Psychological factors are likely often operative but unlikely to be the primary cause. Other oral diseases/disorders/ medications must be ruled out first. The clinicians should better opt for an integrated treatment adequately carried out by a multiprofessional team in order to manage all symptoms and alterations related to BMS. Patient reassurance is paramount. The most promising therapeutic approaches at present include some combination of cognitive behavioral therapy, alpha- lipoic acid and/or clonazepam. Concurrent treatment of any significant psychiatric disorder should also be considered, if present. Furthermore, it is important to have in mind that, in most patients, the disease is self-limiting, not exceeding three years, regardless of the treatment modalities used.

16. Wardrop RW, Hailes J, Burger H. Oral discomfort at the menopause. Oral Surg Oral Med Oral Pathol Oral Radiol Endod 1989;67:535-40.

17. Rojo L, Silvestre FJ, Bagan JV. Psychiatric morbidity in burning mouth syndrome. Psychiatric interview versus depression and anxiety scales. Oral Surg Oral Med Oral Pathol Oral RadiolEndod 1993; 75:308-311.

18. Svensson P, Bjerring P, Arendt-Nielsen L. Sensory and pain thresholds to orofacial argon laser stimulation in patients with chronic burning mouth syndrome. Clin J Pain 1993;9:207-215.

19. Yilmaz Z, Renton T, Yiangou Y, Zakrzewska J, Chessell IP, Bountra C, et al. Burning mouth syndrome as a trigeminal small fibre neuropathy: increased heat and capsaicin receptor TRPV1 in nerve fibres correlates with pain score. J ClinNeurosci 2007; 14(9): 864-871.

20. Gao S, Wang Y, Wang Z. Assessment of trigeminal somatosensory evoked potentials in burning mouth syndrome. Chin J Dent Res 2000; 3(1): 40-46.

21. Hagelberg $N$, Fossell $H$, Aalto $S$, Luutonen $S$,Nagren $K$, Jääskeläinen $S$. Striatal D1 and D2 receptors in burning mouth syndrome. Pain 2003; 101(1/2): 149-154.

22. Epstein JB, Marcoe JH. Topical application of capsaicin for treatment of oral neuropathic pain and trigeminal neuralgia. Oral Surg Oral Med Oral Pathol February 1994 ;77(2):135-40 .

23. Petruzzi M, Lauritano D. Systemic capsaicin for burn-ing mouth syndrome: Short-term results of a pilot study. J Oral Pathol Med 2004; 33(2):111-4

24. Woda A, Navez ML. A possible therapeutic solution for stomatodynia (burning mouth syndrome). J Orofacial Pain 1998; 12(4):272-8.

25. Femiano F, Scully C. Burning mouth syndrome: Double blind controlled study of alpha-lipoic acid (thioctic acid) therapy. J Oral Pathol Med 2002; 31(5):267-9.

26. Bergdahl J, Anneroth G, Perris H. Cognitive therapy in treat $\neg$ ment of patients with resistant burning mouth syndrome: A controlled study. J Oral Pathol Med 1995; 24(5):213-5.

27. Sardella A, Lodi G, DemarosiF, Bez C, Cassano S, Carrassi A. Burning mouth Syndrome: a retrospective study investigating spontaneous remission and response to treatments. Oral Dis 2006; 12(2): 152-155. 